\title{
Citation:
}

Koenen, A., Vervoort, E., Kelchtermans, G., Verschueren, K., Spilt J.L. (2018). Teacher Sensitivity in Interaction with Individual Students: The Role of Teachers' Daily Negative Emotions. European Journal of Special Needs Education (e-publication). 


\title{
Teacher Sensitivity in Interaction with Individual Students: The Role of Teachers' Daily Negative Emotions.
}

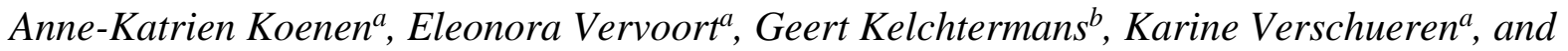
Jantine L. Spilt ${ }^{a}$

${ }^{\text {a }}$ School Psychology and Development in Context, Leuven, Belgium

${ }^{\mathrm{b}}$ Centre for Innovation and the Development of Teacher and School, Leuven, Belgium

\begin{abstract}
Research stresses the importance of teacher sensitivity for the development of special needs students, including students with attachment problems. However, little is known about the antecedents of teacher sensitivity. This study investigated associations between teachers' daily negative emotions and teacher sensitivity towards individual students. Data were collected from 71 teacher-student dyads in special education primary schools and included students with mild to severe attachment problems (6 to 10 years old). Teachers reported their daily negative activating (e.g. anger) and deactivating (e.g. sadness) emotions in relation to individual students during a three-week period. Teacher sensitivity was observed in interaction with the target student in a cognitively-challenging and an emotionallychallenging task. Teachers' higher but decreasing negative activating emotions were associated with higher levels of observed teacher sensitivity in the cognitivelychallenging task. In addition, heightened levels of negative deactivating emotions were associated with lower levels of observed teacher sensitivity but only in the emotionally-challenging task.
\end{abstract}

Keywords. Teacher-Student Interactions, Teacher Sensitivity, Negative Emotions Funding: This study was supported by a grant of the Fund for Scientific Research Flanders (G.0555.09N) to Karine Verschueren. 


\section{Teacher Sensitivity in Interaction with Individual Students: The Role of Teachers' Daily Negative Emotions.}

In their interactions with special needs students, teachers may provide students with a secure base and safe haven in which to express their emotions and to explore the school environment. Teachers' responsiveness to the needs of individual students or teacher sensitivity is important as a proximal antecedent of the quality of teacher-student interactions and relationships (Sabol \& Pianta, 2012; Verschueren \& Koomen, 2012). However, little is known about antecedents of teacher sensitivity in dyadic teacher-student interactions. The current study was conducted in primary schools providing special education and investigated the associations between teachers' daily negative emotions as triggered in the interactions with one specific student on the one hand and teacher sensitivity towards that student on the other.

\section{Teacher Sensitivity}

Attachment theory (Bowlby, 1969/1982) conceptualizes caregiver sensitivity as the awareness and accurate interpretation of a child's signals or needs and the ability to respond to them appropriately. Applied to schooling this implies that sensitive teachers are aware of the social-emotional and academic needs of their students and able to properly respond to them (Hamre \& Pianta, 2005), thereby fostering the quality of teacher-student interactions as well as students' academic and social-emotional development (Howes, Galinsky, \& Kontos, 1998; La Paro, Pianta, \& Stuhlman, 2002; Madill, Gest, \& Rodkin, 2014; Mashburn et al., 2008). Most research studies and evaluates teacher sensitivity towards the whole class group thus investigating a more general teacher sensitivity style (e.g. Buyse, Verschueren, Doumen, 2011; Buyse, Verschueren, Doumen, Van Damme, \& Maes, 2008). However, the quality of teacher-student interactions and teachers' ability to respond sensitively to a student's unique needs differs between students of the same classroom (Hamre \& Pianta, 2001; Pianta, Hamre, 
\& Stuhman, 2003; Thijs, Koomen, \& Van der Leij, 2008). Therefore, this study investigated teacher sensitivity at the dyadic level, that is, in one-on-one relations. So, teacher sensitivity in this study refers to a teacher's responsiveness to an individual student and encompasses a teacher's provision of comfort, reassurance, and encouragement with respect to a students' academic and emotional functioning (Verschueren, Van de Water, Buyse, \& Doumen, 2006).

Teacher sensitivity is important for students in special education (Rimm-Kaufman, Voorhees, Snell, \& La Paro, 2003; Verschueren \& Koomen, 2012), and more in particular for students with attachment problems. Those students often have problems with relationships because they hold low trust in others, due to a history of insufficient caregiving (Riley, 2009; Schwartz \& Davies, 2006). Teachers who respond sensitively to the needs of these students may provide corrective attachment experiences and win the trust of these students. Accordingly, teacher sensitivity has been found to support the attachment needs of these students and to protect them from negative development outcomes (e.g. disruptive behaviour; Kobak, Little, Race, \& Acosta, 2001; Zajac \& Kobak, 2006). However, students with attachment problems are also likely to interact in more socially inappropriate or even aggressive ways because of poor relational skills. Accordingly, interactions between the teacher and a student with attachment problems may be less positive and more conflictual (Kawabata, Alink, Tseng, Van Ijzendoorn, \& Crick, 2011; Schwartz \& Davies, 2006). Teachers of social-emotionally and behaviourally impaired students are more likely to experience negative emotions (Stempien \& Loeb, 2002), which as a consequence may impact teachers' sensitivity towards the students (Kelchtermans \& Deketelaere, 2016; Pekrun, \& Linnenbrink-Garcia, 2014; Schutz \& Zembylas 2009).

\section{Emotions and Teacher Sensitivity}

Emotion research stresses the strong interconnection between emotions and behaviour in social interactions (Baumeister, Vohs, DeWall, \& Zhang, 2007; Russell, 2003). The 
emotions that a teacher repeatedly experiences in interaction with a student may influence his or her (sensitive) behaviour towards the specific student. Previous research has started to untangle the connection between emotions and behaviour in social interactions. Russell (2003) explained that emotions influence one's resources when planning or deciding on actions. The behavioural consequences of emotions result from the general principle of congruency: pleasant emotions facilitate attention to and accessibility of a repertoire of positive actions, whereas negative emotions facilitate attention to and accessibility of a repertoire of negative actions. For example, anxious individuals identify more negativity in emotionally-ambiguous facial expressions, which indicates that emotions influence perceptual attentional processes (Blanchette \& Richards, 2010). In addition, although a situation can be interpreted in multiple ways, an individual's final interpretation of a situation is influenced by that person's affect suggesting an affect-congruent interpretative bias (especially in ambiguous situations). Consequently, the final interpretation is constrained by a person's affective state (Blanchette \& Richards, 2010). For instance, anxious individuals interpret neutral events more negatively: they resolve the ambiguity in line with the more threatening interpretation due to an anxious mood. Taken together, emotions are associated with perceptual-attentional processes and affect-congruent interpretation biases, which in turn is reflected in the behavioural response of the person (Blanchette \& Richards, 2010; Russell, 2003). A teacher, for example, who feels frustrated, anxious or insecure in interactions with a student may be more attentive and more reactive to negative behaviour of this student, with the risk of misinterpreting the student's signals and (special) needs, eventually resulting in diminished teacher sensitivity.

In the parent-child literature it has been found that negative emotions of parents indeed relate to less sensitive parenting behaviour (e.g. Adam, Gunnar, \& Tanaka, 2004; Hastings, Zahn-Waxler, Robinson, Usher, \& Bridges, 2000). Similarly, several studies have 
shown that teachers' emotions affect their daily behaviour towards students (Keller, Frenzel, Goetz, Pekrun, \& Hensley, 2014). Zinsser et al. (2013), for example, reported that teachers' negative emotions and stress undermine their ability to manage emotional challenges and to provide emotional support to students. In addition, Sutton and Weathly (2003) suggested that negative emotional states of teachers may influence how student misbehaviour is attributed, leading to misinterpretations and influencing teachers' choice of action to deal with it. However, despite the evidence that (negative) emotions influence the behaviour of teachers, quantitative research on the connection between teachers' daily negative emotions and teacher sensitivity at a dyadic level is scarce. One exception is Stuhlman and Pianta (2002) who found that teachers' narrative expressions of negative feelings for an individual student were significantly related to observed negative teacher behaviour towards that student. It is likely that this leads to more interaction problems between a teacher and a student, which triggers more negative emotions in the teacher and results in a further decrease in sensitivity (Doumen et al., 2008; Spilt, Koomen, \& Thijs, 2011; Sutherland \& Oswald, 2005).

Negative activating versus deactivating emotions of teachers. The arousal of negative emotions influences one's readiness to take action (Lazarus \& Cohen-Charash, 2001). Therefore, it is meaningful to make a distinction between activating and deactivating emotions (e.g. Chang \& Davis, 2009). Each emotion involves its own innate action tendency, which is either activating or deactivating. For example, the action tendency in anger is attack, which is activating (although this tendency to attack may be inhibited when considered inappropriate or contrary to social rules; Lazarus, 1991; Russell, 2003). In contrast, sadness inactivates, resulting in withdrawal from the situation (Lazarus, 1991).

Negative activating emotions (e.g. anger) may prepare teachers to take action. For example, they may evoke a motivation to intervene with controlling strategies towards a student who is perceived as non-compliant, in order to avoid disruption of a lesson or to 
prevent further misbehaviour. This is consistent with the research of Reyna and Weiner (2001) showing that teacher anger promotes the tendency to respond in a punitive way and a reluctance to provide emotional support, as a consequence of negative attributional reasoning (e.g. student behaviour is more readily interpreted as lazy or manipulative if one is feeling angry).

Negative deactivating emotions (e.g. sadness) foster passivity and impair teachers' engagement, resulting in teachers withdrawing from the student (Chang \& Davis, 2009; Pekrun, Elliot, \& Maier, 2009; Russell, 2003). Research on teachers' negative deactivating emotions is scarce. However, Hamre and Pianta (2004) indicated that teachers who reported more depressed emotions indeed showed less engagement in their interactions with individual students and were less sensitive to the students' needs.

\section{This Study}

This study investigates the associations between daily negative activating and deactivating emotions on the one hand and teacher sensitivity in dyadic teacher-student interactions on the other, in a sample of students with mild to severe attachment problems in schools for special education. We expected that higher (and increasing) levels of negative activating and deactivating emotions in daily interactions with a student would be associated with lower levels of teacher sensitivity. Because student behaviour problems and attachment problems may be associated with teacher sensitivity (e.g. Belsky \& Fearon, 2002; Oosterman, \& Schuengel, 2008), we controlled for attachment and externalizing problems in our analyses.

Reports of negative emotions of the teachers in interaction with an individual student were collected every day during a period of three weeks (Bolger, Davies, \& Rafaeli, 2003). This diary approach allowed to measure teachers' negative emotions on a daily basis (e.g. acknowledging possible fluctuations in emotions) in contrast to a single measurement (i.e. 
conceiving emotions as stable traits; Keller, Frenzel et al., 2014). This is important because, over time, daily negative emotions are likely to shape subsequent teacher-student interactions in a congruent manner (i.e. negative emotions lead to biased interpretations and conflicted interactions), thereby further increasing negative emotion (Spilt et al., 2011; Sutherland \& Oswald, 2005). Accordingly, the use of diary methods allowed to capture the dynamics of negative emotions over time in order to investigate the average intensity as well as the development of teachers' negative emotions for individual students.

Teacher sensitivity was observed in one-to-one teacher-student interactions outside the classroom. This structured setting provided a controlled context, reducing the random error in the measurement that is often caused by the confounding influences of contextual factors (cf., Zaslow et al., 2006). We tested the hypothesis of the impact of teachers' negative emotions on teacher sensitivity in two types of tasks: a cognitively-challenging and an emotionally-challenging task. We assumed that the emotional insecurity of a student would increase in an emotionally-challenging situation and would therefore require a heightened sensitivity of the teacher to the student's emotional needs. Consequently, the impact of teachers' negative emotions on teacher sensitivity to a student's socioemotional needs might be better observable in an emotionally-challenging task. Likewise, the impact of negative emotions on teacher sensitivity to students' academic needs might be more easily observed in a cognitively-challenging task.

\section{Method}

\section{Sample}

In this study, 58 teachers (12\% male) and 71 students ( $82 \%$ boys) participated. The study was conducted in 17 schools providing special education for students with emotional and behavioural disorders. Students with the $75 \%$ highest scores on a validated questionnaire of attachment problems were included (see below). The mean age of the teachers was 33.46 
$(S D=7.13 ;$ range $=22.23$ to 46.14$)$ years, whereas the mean age of the students was 8.35 $(S D=1.00 ;$ range $=6.22$ to 10.39$)$ years. The majority of the students had at least one psychiatric diagnosis (86\%), including autism spectrum disorder, attention deficit hyperactivity disorder, conduct disorder, mental retardation, mood or anxiety disorder, or reactive attachment disorder; $45 \%$ of the students received more than one diagnosis presenting different combinations. All information was collected in the first semester of the school year (fall).

\section{Selection Procedure}

All 38 schools providing special education for students with emotional and behavioural disorders in Flanders (Dutch-speaking region of Belgium) were invited to participate in the study and 21 of the schools agreed. Caregivers of 178 students agreed to take part in the study ( $42 \%$ participation rate) and almost all their teachers were willing to participate in the study (94\%). The selection of the students was based on a scale for attachment problems (students with the $75 \%$ highest scores were included) and a maximum of two students per teacher were selected to reduce the data-collection workload (for more information about the selection procedure, see Vervoort, Verschueren, \& Bosmans, 2013). Although the sample consisted of 85 students of 70 teachers, we removed teachers with crucial missing data on the emotion diaries as well as students with multiple teachers $(n=12$ teachers, -they did not differ significantly on the dependent variable). This eventually resulted in a sample consisting of 71 teacher-student dyads including 58 teachers in 17 schools (13 teachers reported on two students of their class).

\section{Measures}

Negative emotions. The negative emotions of the teachers were collected through a diary over a period of three weeks (Bolger et al., 2003). The dairy method was pilot tested in a small sample of teachers to check for readability, ease of use, and applicability. Teachers 
had to rate the intensity of six negative emotions (anger, guilt, helplessness, irritation, sadness, and tension) on a scale from one to five according to how they felt during that day about the target student $(1=$ '(almost $)$ not', $5=$ 'quite strong'; $90 \%$ of the measurement moments were completed). Three items measured teachers' negative activating emotions (e.g. anger, irritation, and tension; $\alpha=.85$ ) and three items measured teachers' negative deactivating emotions (e.g. sadness, guilt, and helplessness; $\alpha=.68$ ).

To explore the possibility of different patterns in the development of negative activating and deactivating emotions, different latent groups of teacher-student dyads were examined using latent class growth modelling (LCGA, cf., Jung and Wickrama, 2008). Different models up to four latent classes were considered to assess the optimal number of classes (see Table 1). For negative activating emotions, the biggest drop in the Bayesian Information Criterion (BIC) value was found for the two-class model. The Entropy values, indicating the classification quality, suggested that the two- or three-class model had the best fit (highest value). However, the Bootstrap Likelihood Ratio Test (BLRT) favoured the threeclass model over the two-class model $(p \leq .01)$. Based on these results, a three-class model for the negative activating emotions was selected. This solution had latent class probabilities ranging from .932 to .996 referring to an excellent classification accuracy. The majority of the teachers were identified in the Low-stable group $(n=46)$. These teachers were low in experiencing negative emotions and these low levels of negative emotions were stable over time. A smaller amount of teachers were identified in a Higher-decreasing group $(n=19)$ or Higher-increasing group ( $n=6$; see Table 2 and Figure 1). These teachers showed a higher experiencing of negative emotions, which were either decreasing or increasing over time. Regarding the negative deactivating emotions, again different models up to four latent classes were considered (see Table 1). The biggest drop in the BIC value of the models was found for the two-class trajectory model. The Entropy value of the two-class model was the highest 
compared to the other solutions, but was the same for the three-class model. However, the third class only subdivided the second class of the two-class solution. As a result, the more parsimonious two-class solution was selected (cf., Luyckx, Schwartz, Goossens, Soenens, \& Beyers, 2008). In addition, the two-class model was favoured by the Bootstrap Likelihood Ratio Test (BLRT) above the one-class model for the negative deactivating emotions $(p \leq$ .01). Thus, for the negative deactivating emotions a two-class model was selected. Latent class probabilities ranged from .998 to 1.000 referring to an excellent classification accuracy. Most of the teachers were identified in the Low-stable group $(n=60)$ and a small group of teachers were identified in the Higher-increasing group ( $n=11$; see Table 2 and Figure 1$)$.

Observed sensitivity. Teachers' interactions with the target student were observed in two different task settings outside the classroom: a cognitively-challenging Puzzle task and an emotionally-challenging Emotion events task. In the Puzzle task, the student had to solve as many difficult puzzles (smart game) as possible. In the Emotion events task, the student was presented with four cards, on each of which a pictorial representation of a child with the facial expression of a feeling. The feelings were joy, anger, fear, and sadness. The student was asked by the teacher to choose an emotion/card, recall an emotional experience, and tell about what he/she felt, thought, and did. The task was ended when the student had told about his/her emotional experience(s) for each of the four emotions/cards. This task was based on the Autobiographical Emotional Events Dialogue (AEED) of Koren-Karie, Oppenheim, Haimovich, and Etzion-Carasso (2003).

The teachers were instructed to guide and motivate the student in performing the two tasks for the duration of ten minutes each. Teacher-student interactions were video-taped and afterwards coded by trained coders. All teacher-student interactions were double coded using the subscale Sensitivity inspired by the Classroom Assessment Scoring System (CLASS; La Paro, Pianta, \& Stuhlman, 2002). The CLASS was adapted by Verschueren et al. (2006; 
Doumen, Koomen, Buyse, Wouters, Verschueren, 2012) to measure the quality of teacherstudent interactions at the dyadic instead of at the classroom level. For the coding of Sensitivity, the observers had to choose among seven extensive descriptions ranging from 1 (e.g. 'The teacher may not notice or respond to the student when he or she is disengaged, frustrated, or confused during activities') to 7 (e.g. 'A sensitive teacher responds to the students in a soothing and understanding manner, listening carefully to the student and providing appropriate assistance and reassurance.'). The intra class correlation coefficient was .62 for the Puzzle task and .73 for the Emotion events task, indicating good interrater reliability (Cicchetti et al., 2006).

Externalizing problems. Two subscales, Conduct Problems and Hyperactivity, of the Strength and Difficulties Questionnaire (SDQ; Goodman, 1997) were completed by the teachers. The aggregated ten items provide a valid measurement of the Externalizing problems of students ( $\alpha=.83$; Goodman, Ford, Simmons, Gatward, \& Meltzer, 2000; Van Leeuwen, Meerschaert, Bosmans, De Medts, \& Braet, 2006). Each item (e.g. 'This student is restless, overactive and cannot stay still for long') has three possible answers scored 0,1 or 2 ('not true', 'somewhat true', and 'certainly true').

Attachment problems. Ten items of the Relationship Problem Questionnaire (RPQ; Minnis et al., 2007) were used to measure the attachment problems of the students in a valid and reliable way (Minnis et al., 2007; Vervoort, De Schipper, Bosmans, \& Verschueren, 2013). The scale includes ten items (e.g. 'If you approach him/her, he/she often runs away or refuses to be approached'; $\alpha=.81$ ) that are scored from 0 ('not at all like') to 3 ('exactly like'). This questionnaire was presented to the students' former teachers (from the school year preceding the one of this study) as part of the selection procedure of the larger study (see Vervoort, Verschueren et al., 2013).

\section{Analysis}


Latent class mean differences in Sensitivity (equalities of means across classes) were tested in Mplus 7 (Muthén \& Muthén, 2015) separately between the subgroups of negative activating and deactivating emotions. The analyses were run with maximum likelihood parameter estimates with standard errors which are robust to non-normality and including missing data estimation (MLR estimator, Muthén \& Muthén, 2015). In addition, the analyses took into account the multilevel nature of the data (students nested in teachers) with the Cluster-option of Mplus 7.

\section{Results}

Scores for Sensitivity ranged from 3.50 to $6.50(M=5.05 ; S D=0.68)$ in the Puzzle task and from 3.00 to $6.50(M=4.89 ; S D=0.77)$ in the Emotion events task. The correlation between Sensitivity in both tasks was moderate $(r=.34, p \leq .05)$. The last two columns of Table 2 present the descriptive statistics and the group mean differences in sensitivity. Table 3 reports the descriptive statistics for all variables. Attachment and Externalizing problems were not included in the analyses as covariates, because they did not correlate with the dependent variable.

Negative activating emotions and Sensitivity. The group of teachers with higher but decreasing negative activating emotions scored significantly higher on Sensitivity in the Puzzle task as compared to the group of teachers with low and stable negative activating emotions $(d=0.67)$. The group of teachers with higher but increasing negative activating emotions did not differ significantly from the other two groups on Sensitivity in the Puzzle task. No between-group differences were found in the Emotion events task.

Negative deactivating emotions and Sensitivity. The group of teachers with higher and increasing negative deactivating emotions scored significantly lower on Sensitivity in the Emotion events task in comparison to the group of teachers with low and stable negative 
deactivating emotions $(d=-0.61)$. However, no differences between these groups were found in the Puzzle task.

\section{Discussion}

Teacher sensitivity to the needs of individual students with attachment problems is important and may buffer negative developmental outcomes (Spilt et al., 2016; Verschueren \& Koomen, 2012). However, being sensitive to the needs of students with attachment problems can be difficult for teachers because students with attachment problems are likely to interact in more socially inappropriate ways (Schwartz \& Davies, 2006). This study contributed to the understanding of teacher sensitivity to individual students with attachment problems by investigating the impact of teachers' negative emotions on teacher sensitivity. Helping teachers to acknowledge the impact of negative emotions on their perceptions and behaviour, is an important step forward in enhancing teachers' sensitivity to the needs of their students (Kennedy \& Kennedy, 2004).

\section{Negative Emotions and Teacher Sensitivity}

The findings suggested that relatively higher and increasing levels of negative deactivating emotions are associated with lower levels of teacher sensitivity towards individual students, but only in the setting with a task that was emotionally-challenging for students. Teachers experiencing negative deactivating emotions, such as sadness, may misperceive and misinterpret students' signals of emotional distress and therefore ignore or respond insensitively to students' emotional needs (Blanchette \& Richards, 2010). This result can be explained by emotion research indicating that teachers experiencing negative deactivating emotions will be less involved with their students because of an action tendency of withdrawal (Chang \& Davies, 2009; Lazarus, 1991; Russel, 2003). This reasoning is in line with research on caregiver sensitivity, indicating that caregivers with depressive symptoms (i.e. severe levels of negative deactivating emotions) were more withdrawn and less sensitive in their interactions with students (Hamre \& Pianta, 2004). In general, 
depressed persons have a reduced awareness for the emotional states of others and show impairments in empathizing (Dongers et al., 2005). Thus, negative deactivating emotions may impair teachers' emotional awareness and empathy, and as such also impairing teachers' sensitivity to students' emotional needs.

This effect of negative deactivating emotions on teacher sensitivity to students' emotional needs was found in the first semester of the academic year. Repeatedly experiencing negative emotions is likely to shape subsequent teacher-student interactions in a congruent way. Decreased levels of teacher sensitivity may increase conflictual teacherstudent interactions as well as the problem behaviour of the student, thus resulting in a vicious circle of increasing negative emotions and decreasing teacher sensitivity (Doumen et al., 2008; Lazarus, 2006; Spilt et al., 2011; Sutherland \& Oswald, 2005). Accordingly, although the levels of negative emotions were still moderate in this study, the possible impact of increasing levels of negative emotions over time on teacher sensitivity and consequently on students' emotional and academic outcomes may not be underestimated.

Regarding teachers' negative activating emotions, a meaningful difference in teacher sensitivity to students' needs in the cognitively-challenging Puzzle task was found. Interestingly, teacher sensitivity was higher in the group of teachers with higher but decreasing negative activating emotions in comparison with the group of teachers with low and stable negative activating emotions. The negative activating emotions of the former group were higher in the beginning, but decreased over time. This decrease may indicate that the teachers in this group may have been able to manage negative emotions in such a way that negative emotions decreased over time and sensitivity to the student's academic needs could increase (e.g. Spilt, Koomen, Thijs, \& van der Leij, 2012).

\section{Teachers' Emotional Support Across Tasks}


So far, virtually no studies have conducted structured observations in cognitivelychallenging versus emotionally-challenging tasks. The current study, however, provides evidence for the importance of including different types of tasks in observational research. The expected negative impact of negative emotions on sensitivity was only found in the Emotion events task. It is possible that the impact of negative emotions on teacher sensitivity is most evident in situations where students feel distressed or emotionally insecure and in need of teachers' emotional support (cf., separation task of Ainsworth, Blehar, Waters, \& Wall, 2015) and that this association is much weaker in cognitively-challenging situations.

\section{Limitations and Future Research}

Several limitations of this study and suggestions for future research can be raised. First, although the sample was relatively small, every special education school in Flanders was contacted and within schools the participation rate of teachers was $94 \%$. This suggests that there was no biased drop-out (caused by for example teacher stress). The use of the latent class growth analyses provided insight in different patterns of teachers' negative activating and deactivating emotions. However, conclusions need to be drawn with caution because of the low number of teacher-student dyads in some of the groups (due to the small sample). Replication is needed in larger samples to confirm the results of the current study.

Second, this study does not allow to draw any conclusions about causality. Negative emotions can be antecedents as well as outcomes of teachers' sensitivity. Negative emotions of teachers may impair teachers' sensitive behaviour towards students, while conversely, supportive and sensitive teachers may enhance positive interactions between teacher and student and as such reduce the level of negative emotion in teachers (Pianta et al., 2003; Stroet, Opdenakker, \& Minnaert, 2013). Both quantitative (e.g. longitudinal or intervention studies) and qualitative research (e.g. in-depth interviews) are needed to deepen our understanding of such circular transactional processes (cf., Sutherland \& Oswald, 2005). 
Third, the one-on-one tasks outside the classroom allowed to observe dyadic teacherstudent interactions in a systematic and standardized way, while minimizing the influence of contextual confounders (Zaslow et al., 2006). However, this situation differs from a typical classroom situation and as such diminishes the ecological validity.

Future research on teacher emotions should investigate the distinction between (negative) activating and deactivating emotions more in depth, as only very few studies have done so (cf., Chang \& Davies, 2009). Nevertheless, the current study did find differences between the two types of negative emotions in teachers, thus underscoring the need to examine the action tendency of teacher emotions in daily practice. In addition, future research could take teachers' cognitions and perceptions (e.g. misinterpretations of student behaviour, emotion coping strategies) into account to gain a deeper understanding as to why (negative deactivating) emotions undermine teacher sensitivity to students' emotional needs (e.g. Chang, 2009; Keller, Chang, Becker, Goetz, \& Frenzel, 2014). Qualitative research targeting teachers' emotion regulation strategies may provide deeper understanding of teachers' negative emotions and how they manage them. Finally, investigating long-term effects of negative emotions on teacher sensitivity (and students' outcomes), would also constitute a meaningful line of research. It could well be that effects of negative emotions on teacher sensitivity build up over the course of the academic year (see above).

\section{Practical Implications}

The findings of this study stress the importance of supporting teachers with negative deactivating emotions that are triggered in their interactions with individual students. It is important for teachers to develop a clear understanding on the emergence of those negative emotions, how they may lead to ignoring or misunderstandings of students' needs, and eventually may reduce their responsiveness (Chang \& Davis, 2009). Relationship-focused reflection on their interactions with individual students may facilitate teachers' understanding 
of the interrelations between their emotions, thoughts, and behaviour. For example, intervention research has found that relationship-focused reflection is promising to support teacher sensitivity in interactions with individual students (Spilt et al., 2012; see more examples of interventions in Hughes, 2012). In addition, the pedagogies and assignments of student teacher internship (pre-service training) programs as well as in-service training opportunities could have a positive influence by explicitly focussing on strengthening teachers' awareness of the impact of emotions on their sensitivity to their students' needs (Chang, 2009; Kelchtermans \& Deketelaere, 2016; Swartz \& McElwain, 2012). 


\section{References}

Adam, E. K., Gunnar, M. R., \& Tanaka, A. (2004). Adult attachment, parent emotion, and observed parenting behavior: mediator and moderator models. Child development, 75 , $110-122$.

Ainsworth, M. D. S., Blehar, M. C., Waters, E., \& Wall, S. N. (2015). Patterns of attachment: A psychological study of the strange situation. New York, NY: Psychology Press.

Baumeister, R. F., Vohs, K. D., DeWall, C. N., \& Zhang, L. (2007). How emotion shapes behavior: feedback, anticipation, and reflection, rather than direct causation. Personality and Social Psychology Review, 11, 167-203.

Belsky, J., \& Fearon, R. P. (2002). Early attachment security, subsequent maternal sensitivity, and later child development: does continuity in development depend upon continuity of caregiving?. Attachment \& Human Development, 4, 361-387.

Blanchette, I., \& Richards, A. (2010). The influence of affect on higher level cognition: a review of research on interpretation, judgement, decision making and reasoning. Cognition \& Emotion, 24, 561-595.

Bolger, N., Davis, A., \& Rafaeli, E. (2003). Diary methods: capturing as it is lived. Annual Review of Psychology, 54, 579-616.

Bowlby, J. (1969/1982). Attachment and loss: vol. 1. New York, NY: Basic Books.

Buyse, E., Verschueren, K., Doumen, S. (2011). Preschoolers' attachment to mother and risk for adjustment problems in kindergarten: can teachers make a difference?. Social Development, 20, 33-50.

Buyse, E., Verschueren, K., Doumen, S., Van Damme, J., \& Maes, F. (2008). Classroom problem behavior and teacher-child relationships in kindergarten: the moderating role of classroom climate. Journal of School Psychology, 46, 367-391. 
Chang, M. (2009). An appraisal Perspective of teacher Burnout: Examining the emotional work of teachers. Educational Psychology Review, 21, 193-218.

Chang, M., \& Davis, H. (2009). Understanding the role of teachers appraisals in shaping the dynamics of their relationships with students: deconstructing teachers' judgments of disruptive behavior/students. In P.A., Schutz \& M., Zembylas (Eds.), Advances in Teacher Emotion Research: The impact on teachers' lives (pp.95-127). New York: Springer.

Cicchetti, D., Bronen, R., Spencer, S., Haut, S., Berg, A., Oliver, P., \& Tyrer, P. (2006). Rating scales, scales of measurement, issues of reliability: resolving some critical issues for clinicians and researchers. Journal of Nervous and Mental Disease, 194, $557-564$.

Dongers, U., Kersting, A., Dannlowski, U., Lalee-Mentzel, J., Arolt, V., \& Suslow, T. (2005). Reduced awareness of others' emotions in unipolar depressed patients. The Journal of Nervous and Mental Disease, 193, 331-337.

Doumen, S., Koomen, H., Buyse, E., Wouters, S., \& Verschueren, K. (2012). Teacher and observer views on student-teacher relationships: convergence across kindergarten and relations with student engagement. Journal of School Psychology, 50, 61-76.

Doumen, S., Verschueren, K., Buyse, E., Germeijs, V., Luyckx, K., \& Soenens, B. (2008). Reciprocal relations between teacher-child conflict and aggressive behavior in kindergarten: a three-wave longitudinal study. Journal of Clinical Child and Adolescent Psychology, 37, 588-599.

Goodman, R. (1997). The Strengths and Difficulties Questionnaire: a research note. Journal of Child Psychology and Psychiatry, 38, 581-586.

Goodman, R., Ford, T., Simmons, H., Gatward, R., \& Meltzer, H. (2000). Using the strengths 
and difficulties questionnaire (SDQ) to screen for child psychiatric disorders in a community sample. The Britisch Journal of Psychiatry, 177, 534-539.

Hamre, B. K., \& Pianta, R. C. (2001). Early teacher-child relationships and the trajectory of children's school outcomes through eighth grade. Child Development, 72, 625-638.

Hamre, B. K., \& Pianta, R. C. (2004). Self-reported depression in nonfamilial caregivers: prevalence and associations with caregiver behavior in child-care settings. Early Childhood Research Quarterly, 19, 297-318.

Hamre, B. K., \& Pianta, R. C. (2005). Can instructional and emotional support in the firstgrade classroom make a difference for children at risk of school failure? Child Development, 76, 949-967.

Hastings, P. D., Zahn-Waxler, C., Robinson, J., Usher, B., and Bridges, D. (2000). The development of concern for others in children with behavior problems. Developmental Psychology, 36, 531-546.

Howes, C., Galinsky, E., \& Kontos, S. (1998). Child care caregiver sensitivity and attachment. Social Development, 7, 25-36.

Hughes, J. N. (2012). Teacher-student relationships and school adjustment: progress and remaining challenges. Attachment \& Human Development, 14, 319-327.

Jung, T., \& Wickrama, K. A. S. (2008). An introduction to latent class growth analysis and growth mixture modeling. Social and Personality Psychology Compass, 2, 302-314.

Kawabata, Y., Alink, L. R., Tseng, W.-L., Van Ijzendoorn, M. H., \& Crick, N. R. (2011). Maternal and paternal parenting styles associated with relational aggression in children and adolescents: a conceptual analysis and meta-analytic review. Developmental Review, 31, 240-278.

Kelchtermans, G., \& Deketelaere, A. (2016). The emotional dimension in becoming a 
teacher. In: Loughran J., Hamilton M. (Eds.), International Handbook of Teacher Education. Volume 2 (pp. 429-461). Dordrecht: Springer.

Keller, M. M., Chang, M.-L., Becker, E. S., Goetz, T., \& Frenzel, A. C. (2014). Teachers' emotional experiences and exhaustion as predictors of emotional labor in the classroom: an experience sampling study. Frontiers in Psychology, 5, 1442.

Keller, M. M., Frenzel, A. C., Goetz, T., Pekrun, R., \& Hensley, L. (2014). Exploring teacher emotions. In P.W. Richardson, S.A., Karabenick, \& H.M.G. Watt (Eds.) Teacher motivation: Theory and Practice. New York, NY: Routledge.

Kennedy, J. H., \& Kennedy, C. E. (2004). Attachment theory: implications for school psychology. Psychology in the Schools, 41, 247-259.

Kobak, R., Little, M., Race, E., \& Acosta, M. C. (2001). Attachment disruptions in seriously emotionally disturbed children: implications for treatment. Attachment \& Human Development, 3, 243-258.

Koren-Karie, N., Oppenheim, D., Haimovich, Z., \& Etzion-Carasso, A (2003). Dialogues of seven-year olds with their mothers about emotional events: development of typology. In R. N. Emde, D. P. Wolf, and D. Oppenheim, (Eds.), Revealing the inner world of young children: The MacArthur story stem battery and parent- child narratives (pp 338-354). New York, NY: Oxford University Press.

La Paro, K. M., Pianta, R. C., \& Stuhlman, M. W. (2002). Classroom Assessment Scoring System (CLASS). Charlottesville: University of Virginia.

Lazarus, R.S. (1991). Progress on a cognitive-motivational-relational theory of emotion. American Psychologist, 46, 819-834.

Lazarus, R. S. (2006). Stress and emotion: A new synthesis. New York, NY: Springer.

Lazarus, R. S., \& Cohen-Charash, Y. (2001). Discrete emotions in organizational life. In R. 
L. Payne \& G. L. Cooper (Eds.), Emotions at work: Theory, research and applications for management (pp. 45-81). Chichester, England: John Wiley \& Sons.

Luyckx, K., Schwartz, S. J., Goossens, L., Soenens, B., \& Beyers, W. (2008). Developmental typologies of identity formation and adjustment in emerging adulthood: a latent class growth analysis approach. Journal of Research on Adolescence, 18, 595-619.

Madill, R. A., Gest, S. D., \& Rodkin, P. C. (2014). Students' perceptions of relatedness in the classroom: the roles of emotionally supportive teacher-child interactions, children's aggressive-disruptive behaviors, and peer social preference. School Psychology Review, 43, 86.

Mashburn, A. J., Pianta, R. C., Hamre, B. K., Downer, J. T., Barbarin, O., Bryant, D., et al. (2008). Measures of classroom quality in prekindergarten and children's development of academic, language, and social skills. Child Development, 79, 732-749.

Minnis, H., Reekie, J., Young, D., O’Connor, T., Ronald, A., Grayand, A., et al. (2007). Genetic, environmental and gender influences on attachment disorder behaviors. British Journal of Psychiatry, 190, 490-495.

Muthén, L.K., \& Muthén, B.O. (2015). Mplus User's Guide. Seventh Edition. Los Angeles, CA: Muthén \& Muthén.

Oosterman, M., \& Schuengel, C. (2008). Attachment in foster children associated with caregivers' sensitivity and behavioral problems. Infant Mental Health Journal, 29(6), 609-623.

Pekrun, R., Elliot, A.J., \& Maier, M.A. (2009). Achievement goals and achievement emotions: testing a model of their joint relations with academic performance. Journal of Educational psychology, 101, 115-135.

Pekrun, R., \& Linnenbrink-Garcia, L. (2014). International Handbook of Emotions in Education. New York, NY: Routledge. 
Reyna, C., \& Weiner, B. (2001). Justice and utility in the classroom: an attributional analysis of the goals of teachers' punishment and intervention strategies. Journal of educational Psychology, 93, 309-319.

Pianta, R.C., Hamre, B., \& Stuhlman, M. (2003). Relationships between teachers and children. In W.M. Reynolds, \& G.E. Miller (Eds.), Handbook of psychology (pp. 199234). New York: John Wiley \& Sons.

Riley, P. (2009). An adult attachment perspective on the student-teacher relationship \& classroom management difficulties. Teaching and Teacher Education, 25, 626-635.

Rimm-Kaufman, S. E., Voorhees, M. D., Snell, M. E., \& La Paro, K. M. (2003). Improving the sensitivity and responsivity of preservice teachers toward young children with disabilities. Topics in Early Childhood Special Education, 23(3), 151-163.

Russell, J.A. (2003). Core affect and the psychological construction of emotion. Psychological Review, 110, 145-172.

Sabol, T. J., \& Pianta, R. C. (2012). Recent trends in research on teacher-child relationships. Attachment \& Human Development, 14, 213-231.

Schutz, P.A. \& Zembylas, M. (2009). Advances in Teacher Emotion Research: the impact on teachers' lives. New York, NY: Springer.

Schwartz, E., \& Davies, A.S. (2006). Reactive attachment disorder: implications for school readiness and school functioning. Psychology in the School, 43, 471-479.

Spilt, J. L., Koomen, H. M.Y., \& Thijs, J. T. (2011). Teacher Wellbeing: the importance of teacher-student relationships. Educational Psychology Review, 23, 457-477.

Spilt, J.L., Koomen, H.M.Y., Thijs, J.T., \& van der Leij, A. (2012). Supporting teachers' relationships with disruptive children: the potential of relationship-focused reflection. Attachment \& Human Development, 14, 305-318.

Spilt J., Vervoort E., Koenen A., Bosmans G., \& Verschueren K. (2016). The socio- 
behavioral development of children with symptoms of attachment disorder: an observational study of teacher sensitivity in special education. Research in Developmental Disabilities, 56, 71-82.

Stempien, L.R., \& Loeb, R.C. (2002). Differences in job satisfaction between general education and special education teachers. Remedial and special education, 23, 258267.

Stroet, K., Opdenakker, M.-C., Minnaert, A. (2013). Effects of need supportive teaching on early adolescents' motivation and engagement: a review of the literature. Educational Research Review, 9, 65-87.

Stuhlman, M.W., \& Pianta, R.C. (2002). Teachers' narratives about their relationships with children: associations with behavior in classrooms. School Psychology Review, 31, $148-163$.

Sutherland, K. S., \& Oswald, D. P. (2005). The relationship between teacher and student behavior in classrooms for students with emotional and behavioral disorders: Transactional processes. Journal of Child and Family Studies, 14, 1-14.

Sutton, R.E., \& Wheatley, K.F. (2003). teachers' emotions and teaching: a review of the literature and directions for future research. Educational Psychology Review, 15, 327358.

Swartz, R. A., \& McElwain, N. L. (2012). Preservice teachers' emotion-related regulation and cognition: associations with teachers' responses to children's emotions in early childhood classrooms. Early Education \& Development, 23, 202-226.

Thijs, J. T., Koomen, H. M., \& Van der Leij, A. (2008). Teacher-child relationships and pedagogical practices: considering the teacher's perspective. School Psychology Review, 37, 244.

Van Leeuwen, K., Meerschaert, T., Bosmans, G., De Medts, L., \& Braet, C. (2006). The 
Strengths and Difficulties Questionnaire in a community sample of young children in Flanders. European Journal of Psychological Assessment, 22, 189-197.

Verschueren, K., \& Koomen, H. M. (2012). Teacher-child relationships from an attachment perspective. Attachment \& Human Development, 14, 205-211.

Verschueren, K., Van de Water, G., Buyse, E., \& Doumen, S. (2006). Adaptation of the Classroom Assessment Scoring System-Kindergarten to measure the individual teacher-child relationship [in Dutch]. Centrum voor Schoolpsychologie, KU Leuven.

Vervoort, E., de Schipper, J. C., Bosmans, G., \& Verschueren, K. (2013). Screening symptoms of reactive attachment disorder: evidence for measurement invariance and convergent validity. International Journal of Methods in Psychiatric Research, 22, 256-265.

Vervoort, E., Verschueren, K. (sup.), Bosmans, G. (cosup.) (2013). Teacher-child relationships and indiscriminate friendliness in early elementary school children: Measurement, challenges, and protective effects [Unpublished Doctoral Thesis]. KU Leuven, Faculteit Psychologie en Pedagogische Wetenschappen, School- en Ontwikkelingspsychologie van Kind en Adolescent, Leuven.

Zajac, K., \& Kobak, R. (2006). Attachment. In G. G. Bear \& K. M. Minke (Eds.), Children's needs III: Development, prevention and intervention, (pp. 379-389). Washington, DC: National Association of School Psychologists.

Zinsser, K. M., Bailey, C., Curby, T. W., Denham, S. A., \& Bassett, H. H. (2013). Exploring the predictable classroom: preschool teacher stress, emotional supportiveness, and students' social-emotional behavior in private and Head Start classrooms. National Head Start Association Dialog, 16, 90-108.

Zaslow, M. J., Weinfield, N. S., Gallagher, M., Hair, E. C., Ogawa, J. R., Egeland, B., . . De 
Temple, J. M. (2006). Longitudinal prediction of child outcomes from differing measures of parenting in a low-income sample. Developmental Psychology, 42, 27-37. 


\section{Tables}

Table 1

Results of the Latent Class Growth Analysis for Negative Activating and Deactivating

Emotions

Trajectory Class Prevalence $(N=71)$

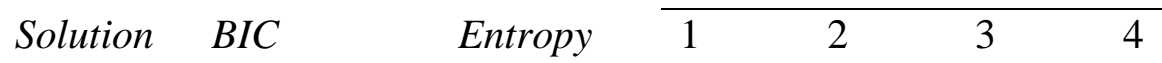

Trajectory models of negative activating emotions

$\begin{array}{llll}1 \text {-class } & 2383.11 \quad-\quad 71\end{array}$

2-class $\quad 2195.15 \quad 0.95 \quad 55 \quad 16$

$\begin{array}{llllll}3 \text {-class } & 2176.45 & 0.95 & 46 & 19 & 6\end{array}$

$\begin{array}{lllllll}\text { 4-class } & 2170.96 & 0.82 & 37 & 18 & 13 & 3\end{array}$

Trajectory models of negative deactivating emotions

$\begin{array}{llll}1 \text {-class } & 1137.72 & - & 71\end{array}$

$\begin{array}{lllll}2 \text {-class } & 861.03 & 1.00 & 60 & 11\end{array}$

$\begin{array}{llllll}3 \text {-class } & 827.26 & 1.00 & 60 & 9 & 2\end{array}$

$\begin{array}{lllllll}\text { 4-class } & 833.82 & 0.98 & 60 & 6 & 3 & 2\end{array}$

Note. BIC, Bayesian Information Criterion. The solutions in bold were selected. 
Table 2

Parameter Estimates for the Latent Trajectory Classes of Negative Activating and Deactivating Emotions, and differences in Observed Sensitivity $(N=71)$

\begin{tabular}{lcccc}
\hline & & & \multicolumn{2}{c}{ Sensitivity } \\
& Intercept & Slope & Puzzle task & Emotion \\
Trajectory classes & Est. $(S E)$ & Est. $(S E)$ & $M(S D)$ & $M(S D)$ \\
\hline & Negative activating emotions & & \\
Low-stable group $(n=46)$ & $1.32(0.04)^{* *}$ & $-0.00(0.01)$ & $4.91(0.63)^{\mathrm{a}}$ & $4.90(0.76)^{\mathrm{x}}$ \\
Higher-decreasing group $(n=19)$ & $2.27(0.13)^{* *}$ & $-0.04(0.01)^{* *}$ & $5.33(0.63)^{\mathrm{b}}$ & $4.86(0.84)^{\mathrm{x}}$ \\
Higher-increasing group $(n=6)$ & $2.09(0.19)^{* *}$ & $0.07(0.03)^{*}$ & $5.29(0.97)^{\mathrm{a} / \mathrm{b}}$ & $4.96(0.78)^{\mathrm{x}}$ \\
& Negative deactivating emotions & & \\
Low-stable group $(n=60)$ & $1.10(0.02)^{* *}$ & $-0.00(0.00)$ & $5.02(0.68)^{\mathrm{a}}$ & $4.96(0.78)^{\mathrm{x}}$ \\
Higher-increasing group $(n=11)$ & $1.47(0.10)^{* *}$ & $0.03(0.01)^{* *}$ & $5.25(0.68)^{\mathrm{a}}$ & $4.52(0.65)^{\mathrm{y}}$ \\
\hline Note. ${ }^{* *} p \leq .01,{ }^{*} p \leq .05 ;$ Different indices indicate significant mean differences between classes $(p \leq .05)$ &
\end{tabular}


Table 3

Descriptive Statistics of all Variables

\begin{tabular}{|c|c|c|c|c|c|c|}
\hline & $M(S D)$ & 1. & 2. & 3. & 4. & 5. \\
\hline 1. Sensitivity -Puzzle task & $5.05(0.68)$ & - & & & & \\
\hline 2. Sensitivity -Emotion events task & $4.89(0.77)$ & $.34 * *$ & - & & & \\
\hline 3. Attachment problems & $0.60(0.48)$ & .20 & .12 & - & & \\
\hline 4. Externalizing problems & $0.90(0.46)$ & -.02 & -.12 & $.53 * *$ & - & \\
\hline 5. Negative activating emotions ${ }^{\circ}$ & $1.58(0.47)$ & .20 & .02 & $.27 *$ & $.48 * *$ & - \\
\hline 6. Negative deactivating emotions ${ }^{\circ}$ & $1.19(0.28)$ & .15 & -.14 & .02 & .12 & $.56^{* *}$ \\
\hline
\end{tabular}




\section{Figure}
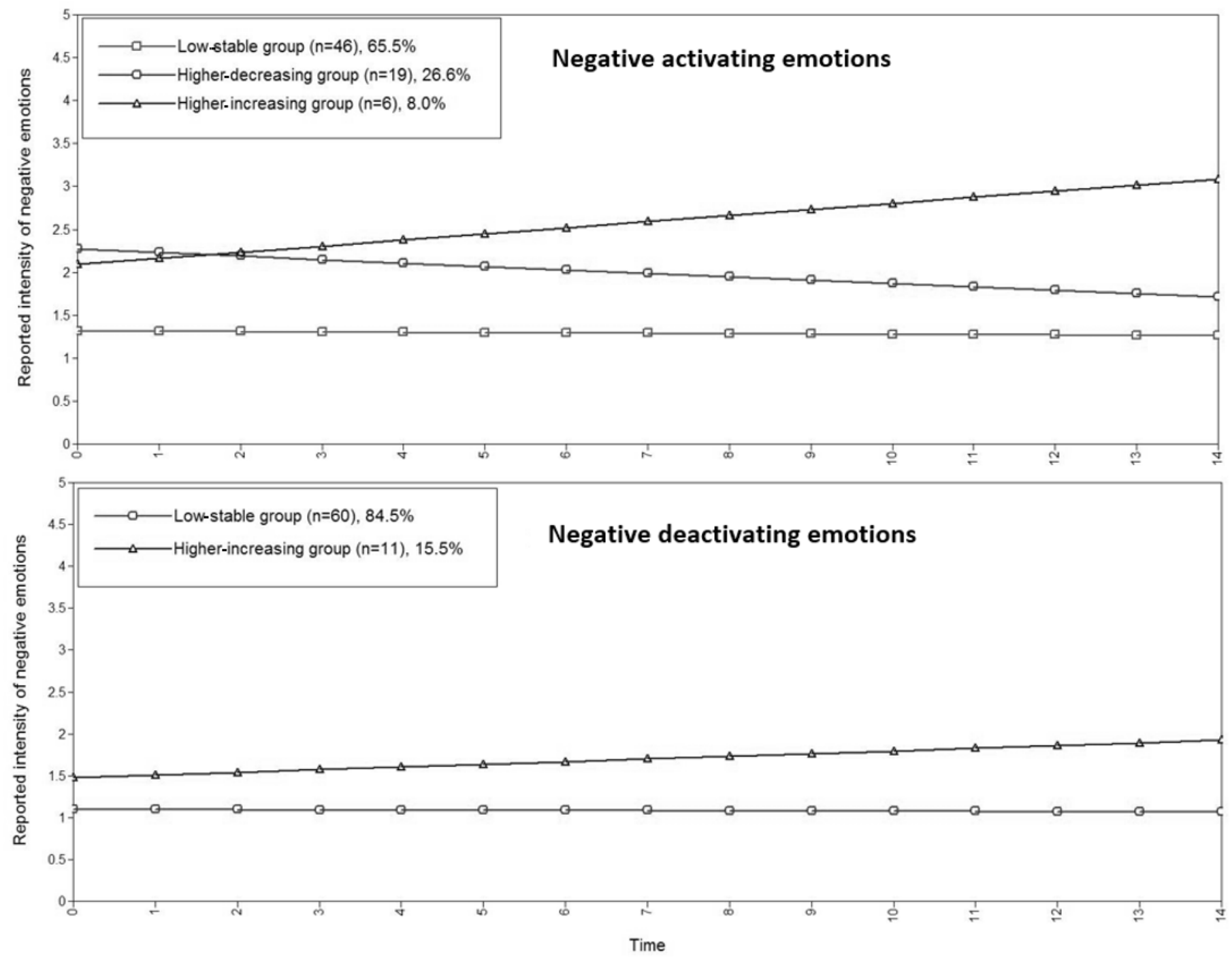

Figure 1. Graphic representation of the 3-class growth model estimation for (1) negative activating emotions and the 2-class growth model estimation for (2) negative deactivating emotions. 